\title{
BMJ Open Long-term follow-up results in patients undergoing percutaneous coronary intervention (PCI) with drug-eluting stents: results from a single high-volume PCI centre
}

\author{
Hai-Mu Yao, ${ }^{1}$ You-Dong Wan, ${ }^{2}$ Xiao-Juan Zhang, ${ }^{2}$ De-Liang Shen, ${ }^{1}$ \\ Jin-Ying Zhang, ${ }^{1}$ Ling Li, ${ }^{1}$ Luo-Sha Zhao, ${ }^{1}$ Tong-Wen Sun ${ }^{2}$
}

To cite: Yao H-M, Wan Y-D, Zhang X-J, et al. Long-term follow-up results in patients undergoing percutaneous coronary intervention $(\mathrm{PCl})$ with drug-eluting stents: results from a single high-volume $\mathrm{PCl}$ centre. $B M J$ Open 2014;4:e004892. doi:10.1136/bmjopen-2014004892

- Prepublication history for this paper is available online. To view these files please visit the journal online (http://dx.doi.org/10.1136/ bmjopen-2014-004892).

Received 20 January 2014 Revised 23 June 2014 Accepted 4 July 2014

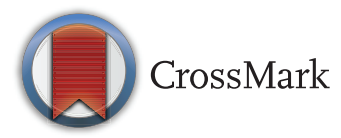

For numbered affiliations see end of article.

Correspondence to Professor Tong-Wen Sun, Department of Integrated Intensive Care Unit, The First Affiliated Hospital, Zhengzhou University, 1 Jianshe East Road, Zhengzhou 450052, People's Republic of China; suntongwen@163.com

\section{ABSTRACT}

Objective: To assess both short-term and long-term prognosis in consecutive patients with coronary heart disease treated with drug-eluting stents in a high-volume percutaneous coronary intervention $(\mathrm{PCl})$ centre.

Design: Observational cohort study.

Setting: A hospital in the Henan province, China, between 2009 and 2011.

Participants: A total of 2533 patients were enrolled. Patients with ST-elevation myocardial infarction (STEMI) treated with urgent PCI accounted for $3.9 \%$ of cases; patients with STEMI treated with delayed PCI accounted for $20.5 \%$ of cases; patients with stable angina accounted for $16.5 \%$ of cases; and patients with non-ST elevation acute coronary syndrome (NSTE-ACS) accounted for $58.6 \%$ of cases.

Primary outcomes: Death, major adverse cardiac and cerebrovascular events (MACCE: death/myocardial infarction/stroke), and target vessel revascularisation.

Results: Follow-up after a median of 29.8 months was obtained for 2533 patients $(92.6 \%)$. The mortality rate during hospitalisation was highest in the urgent $\mathrm{PCl}$ group $(p<0.001)$. During follow-up, although the incidences of death and MACCE were highest in the urgent PCI group, no significant differences were observed among the different groups. The incidences of cardiac death and myocardial infarction were significantly higher in the paclitaxel-eluting stent (PES) group than in the sirolimus-eluting stent (SES) group. Independent predictors of death during follow-up were age, left ventricular ejection function $<40 \%$, diabetes mellitus, prior coronary artery bypass graft and chronic total occlusion.

Conclusions: PCI patients with STEMI had the worst hospital and long-term prognosis. The mortality rate after hospital increased markedly in patients with NSTEACS. SESs seem to be more effective than PESs.

\section{INTRODUCTION}

Coronary heart disease (CHD) is one of the greatest challenges of contemporary medicine.

\section{Strengths and limitations of this study}

- This study assessed early and long-term prognosis in consecutive Chinese patients at different stages of coronary heart disease (CHD) (stable CHD, acute coronary syndrome).

- The study analysed the prognosis of a comprehensive range of patients treated with drug-eluting stents. The end points included death, myocardial infarction, stroke, target vessel revascularisation, in-stent restenosis and stent thrombosis.

- This is an observational single-centre registry study.

Myocardial revascularisation, that is, percutaneous coronary intervention (PCI) and coronary artery bypass graft (CABG), is of great importance in the proper treatment of CHD. Drug-eluting stents (DESs) are currently used to reduce restenosis rates and the need for target vessel revascularisation (TVR) in a variety of patients with significant coronary artery stenosis presenting with either stable angina (SA) pectoris or acute coronary syndromes (ACS).

Observational studies ${ }^{1-3}$ and randomised controlled clinical trials ${ }^{4-9}$ have shown a marked reduction in restenosis and TVR rates with sirolimus-eluting stents (SESs) and paclitaxel-eluting stents (PESs) compared with bare metal stents (BMSs). Data from registries, which reflect the clinical use of DESs in a more inhomogeneous daily clinical practice population, have confirmed these findings. ${ }^{10}{ }^{11}$ However, data from registries on long-term follow-up, especially in the Chinese population, are sparse. In addition, advances in interventional cardiology within the last few years have contributed to the 
improvement of CHD therapy results; thus, it is necessary to perform a periodic assessment of the treatments. The aim of this study was to assess both the early and long-term prognosis in all patients with CHD treated with DESs in a high-volume PCI centre in China.

\section{METHODS}

Study population

The study was carried out on consecutively enrolled patients who underwent PCI between July 2009 and August 2011, at a single high-volume PCI centre. Only patients treated with at least one DES and who completed long-term follow-up documentation were recruited to the study. Qualitative and quantitative coronary angiographic analyses were carried out according to standard methods. PCI was performed using standard techniques. All patients were given loading doses of aspirin $(300 \mathrm{mg})$ and clopidogrel $(300 \mathrm{mg})$ before coronary intervention, unless they had already received antiplatelet medication. The treatment strategy, stenting techniques, selection of stent type, and use of glycoprotein IIb/IIIa receptor inhibitors or intravascular ultrasound were all left to the surgeon's discretion. All patients were prescribed $100 \mathrm{mg}$ /day aspirin indefinitely and clopidogrel $75 \mathrm{mg} /$ day for at least the first 12 months after the procedure. Patients were divided into four groups according to their clinical presentation and timing of PCI as follows: patients with ST-elevation myocardial infarction (STEMI) treated with urgent PCI (urgent PCI) accounted for $3.9 \%$ of cases, patients with STEMI treated with delayed PCI (delayed PCI) accounted for $20.5 \%$ of cases, patients with SA accounted for $16.5 \%$ of cases and patients with non-ST elevation ACS(NSTE-ACS) accounted for $58.6 \%$ of cases. The NSTE-ACS group consisted of patients with non-ST elevation myocardial infarction (MI) and patients with unstable angina.

\section{Definitions used in the study}

Cardiovascular risk factors were assessed at the time of hospital admission. Patients were considered as having a history of smoking if they had smoked within the previous 10 years. Patients were classed as having diabetes mellitus if their fasting plasma glucose concentration was $>6.1 \mathrm{mmol} / \mathrm{L}$, their haemoglobin A1c level was $>6.5 \%$, or they were currently being treated with insulin or oral hypoglycaemic agents. Patients were defined as having hypertension if their systolic blood pressure was $\geq 140 \mathrm{~mm} \mathrm{Hg}$, or their diastolic blood pressure was $\geq 90 \mathrm{~mm} \mathrm{Hg}$ or they were prescribed antihypertensive drugs. Patients were diagnosed with dyslipidaemia if their low-density lipoprotein cholesterol concentration was $>140 \mathrm{mg} / \mathrm{dL}$, their high-density lipoprotein concentration was $<40 \mathrm{mg} / \mathrm{dL}$ or they were prescribed lipid-lowering drugs. Renal insufficiency was defined as a creatinine concentration of $>150 \mathrm{mmol} / \mathrm{L}$. TVR was defined as a repeat procedure, either PCI or CABG, in the target vessel. Stent thrombosis was either proven by angiography or assumed as probable if an unexplained sudden death occurred within 30 days after stent implantation or if a Q-wave MI was diagnosed in the distribution area of the stented artery. This classification was issued according to definitions proposed by the Academic Research Consortium. ${ }^{12}$

\section{Clinical outcomes and data collection}

Prospective data were entered into a database that contained demographic, clinical, angiographic and procedural information. Primary end points included all-cause mortality and the occurrence of MI, stent thrombosis, and TVR. The composite end points were defined as major adverse cardiac and cerebrovascular events (MACCE), namely death, MI and stroke. Clinical follow-up was carried out through patient visits, telephone interviews and medical record reviews. Independent research personnel entered the data and an independent committee adjudicated clinical events. Between July 2009 and August 2011, 2735 patients at our hospitals were treated with at least one DES. Follow-up after a median of 29.8 months (quartiles, 25.634 months) was carried out on 2533 patients (92.6\%).

\section{Statistics}

The distribution of variables was assessed using the Kołmogorov-Smirnov test followed by the Student t test, ANOVA or Mann-Whitney test for comparative analysis; the choice of test depended on the distribution of variables. Categorical variables were expressed as percentages and were analysed using the $\chi^{2}$ test or Fisher's exact test. Cox proportional hazards analyses were used to identify risk factors for the occurrence of death, MACCE and TVR during follow-up. All baseline, demographic, clinical and angiographic variables were entered into the model. Results are reported as HRs and 95\% CIs. All statistical tests were two-tailed, and $\mathrm{p}$ values were statistically significant at $<0.05$. All data were analysed using SPSS V.18.0 software (SPSS, Inc, Chicago, Illinois, USA).

\section{RESULTS}

\section{Characteristics of the study groups}

The demographic characteristics of the 2533 patients enrolled in the study are shown in table 1 . The mean age was $59.9 \pm 11.1$ years and $68 \%$ of patients were men. Patients in the urgent PCI group were younger and predominantly men. Patients in the delayed PCI group had the lowest left ventricular ejection fraction (LVEF). Patients with SA were older and had the highest frequency of past MI and a history of previous revascularisation procedures. The percentage of patients with a history of hypertension was significantly higher in the NSTE-ACS group than in the other groups $(p<0.001)$. Patients with delayed PCI had the highest frequencies of dyslipidaemia and renal insufficiency. 
Table 1 Baseline characteristics of the study population according to clinical presentation

\begin{tabular}{|c|c|c|c|c|c|c|}
\hline & $\begin{array}{l}\text { Urgent } \\
\text { PCI }(n=99)\end{array}$ & $\begin{array}{l}\text { Delayed } \\
\text { PCI (520) }\end{array}$ & $\begin{array}{l}\text { NSTE-ACS } \\
(1496)\end{array}$ & $\begin{array}{l}\text { SA } \\
(n=418)\end{array}$ & $\begin{array}{l}\text { Total } \\
(n=2533)\end{array}$ & p Value \\
\hline Age (years) & $58 \pm 12.6$ & $57.9 \pm 11.5$ & $60.5 \pm 10.8$ & $61 \pm 10.9$ & $59.9 \pm 11.1$ & $<0.001$ \\
\hline Male gender, n (\%) & $79(80.6)$ & 397 (76.2) & 948 (63.3) & 301 (71.8) & $1723(68)$ & $<0.001$ \\
\hline BMI $\left(\mathrm{kg} / \mathrm{m}^{2}\right)$ & $22.5 \pm 3.95$ & $22.9 \pm 4.03$ & $24.3 \pm 3.6$ & $24.1 \pm 3.6$ & $23.9 \pm 3.8$ & $<0.001$ \\
\hline Systolic BP (mm Hg) & $98.9 \pm 26.7$ & $99.2 \pm 28.5$ & $103.6 \pm 28.4$ & $109.4 \pm 30.2$ & $103.3 \pm 28.8$ & $<0.001$ \\
\hline Diastolic BP (mm Hg) & $76.8 \pm 13.9$ & $76.6 \pm 12.6$ & $77.0 \pm 11.6$ & $78.9 \pm 12.3$ & $77.2 \pm 12.0$ & 0.109 \\
\hline Prior $\mathrm{PCl}, \mathrm{n}(\%)$ & $3(3)$ & $13(2.5)$ & $116(7.8)$ & $40(9.5)$ & $172(6.8)$ & $<0.001$ \\
\hline Prior CABG, n (\%) & $0(0)$ & $0(0)$ & $18(1.2)$ & $3(0.7)$ & $21(0.8)$ & 0.05 \\
\hline OMI, n (\%) & $2(2)$ & $14(2.7)$ & $70(4.7)$ & $149(35.6)$ & $235(9.3)$ & $<0.001$ \\
\hline PVD, n (\%) & $0(0)$ & $1(0.2)$ & $2(0.1)$ & $3(0.7)$ & $6(0.2)$ & 0.169 \\
\hline LVEF (\%) & $59.2 \pm 6.63$ & $57.4 \pm 8.14$ & $62.5 \pm 6.38$ & $59.4 \pm 8.58$ & $60.9 \pm 7.45$ & $<0.001$ \\
\hline LVEF $\leq 40 \%, \mathrm{n}(\%)$ & $0(0)$ & $10(2.9)$ & $12(1.2)$ & $15(6.3)$ & $37(2.3)$ & $<0.001$ \\
\hline \multicolumn{7}{|l|}{ Risk factors, $\mathrm{n}(\%)$} \\
\hline Hypertension & 39 (39.4) & $217(41.7)$ & $826(55.2)$ & $164(39.2)$ & 1249 (49.2) & $<0.001$ \\
\hline Diabetes mellitus & $23(23.2)$ & $104(20)$ & $322(21.6)$ & $72(17.3)$ & $521(20.6)$ & 0.234 \\
\hline Dyslipidaemia & $57(58.3)$ & $321(61.8)$ & $800(53.5)$ & $201(48.1)$ & $1379(54.4)$ & $<0.001$ \\
\hline Current smoker & $38(38.4)$ & $180(34.5)$ & $373(25)$ & $80(19.1)$ & $671(26.5)$ & $<0.001$ \\
\hline Renal insufficiency & $0(0)$ & $12(2.3)$ & $13(0.9)$ & $3(0.7)$ & $28(1.1)$ & 0.026 \\
\hline Presence of shock, $n(\%)$ & $3(3)$ & $1(1.2)$ & $0(0)$ & $0(0)$ & $4(0.2)$ & $<0.001$ \\
\hline $\mathrm{TC}(\mathrm{mmol} / \mathrm{L})$ & $4.47 \pm 0.99$ & $4.13 \pm 0.12$ & $4.31 \pm 1.08$ & $4.18 \pm 1.05$ & $4.26 \pm 1.06$ & 0.92 \\
\hline $\mathrm{TG}(\mathrm{mmol} / \mathrm{L})$ & $1.73 \pm 0.89$ & $1.78 \pm 1.04$ & $1.99 \pm 1.48$ & $1.81 \pm 1.1$ & $1.91 \pm 135$ & 0.162 \\
\hline LDL-C (mmol/L) & $2.99 \pm 0.99$ & $2.59 \pm 0.87$ & $2.7 \pm 0.95$ & $2.59 \pm 0.91$ & $2.67 \pm 0.94$ & 0.177 \\
\hline HDL-C (mmol/L) & $1.04 \pm 0.26$ & $0.99 \pm 0.29$ & $1.09 \pm 0.33$ & $1.05 \pm 0.31$ & $1.06 \pm 0.32$ & 0.001 \\
\hline Glycaemia (mmol/L) & $7.97 \pm 3.5$ & $6.61 \pm 5.17$ & $5.78 \pm 2.14$ & $5.8 \pm 2.15$ & $6.05 \pm 3.15$ & $<0.001$ \\
\hline
\end{tabular}

\section{Angiographic findings and interventional characteristics}

The most complex lesions were found in the NSTE-ACS and SA groups. The study groups did not differ in interventional characteristics, except that the frequency of left anterior descending coronary artery intervention was higher in the delayed PCI group, and the frequency of left circumflex coronary artery intervention was higher in the SA group (table 2).

\section{In-hospital and follow-up events}

In-hospital event rates were low. The mortality rate was highest in the urgent PCI group and lowest in the SA group $(p<0.001)$. The incidence of major adverse cardiac events was highest in the urgent PCI group and lowest in the NSTE-ACS group ( $\mathrm{p}=0.001)$.

During the mean follow-up of 29 months, the incidences of death and MACCE were highest in the urgent PCI group, but no significant differences were observed among the groups. The frequency of TVR was highest in the SA group and lowest in the urgent PCI group $(p=0.001)$. The frequency of in-stent restenosis was highest in the NSTE-ACS group and lowest in the delayed PCI group ( $\mathrm{p}=0.048$ ) (table 3 ).

To estimate the effect of different DESs on clinical outcomes, we conducted a sub-analysis. In total, 1650 patients were treated with SESs, 504 patients with PESs and 379 patients with a mixture of different types of
DESs. The baseline and procedural characteristics according to whether patients were treated with SESs or PESs are shown in table 4. Significant differences were observed between the two groups in terms of the number of treated vessels, the number of stents per patient, the total stent length per patient and the stent diameter. During the follow-up, the incidences of cardiac death and MI were significantly higher in the PES group than in the SES group. Although the incidence of TVR was also higher in the PES group than in the SES group, this was not statistically significant $(\mathrm{p}>0.05)$ (table 5).

According to Cox proportional hazards analysis, age, LVEF $<40 \%$, prior CABG, diabetes mellitus, and chronic total occlusion were identified as independent predictors of death. Furthermore, age, LVEF $<40 \%$, multi-vessel disease, diastolic blood pressure, chronic total occlusion and left main (LM) target vessel were identified as independent predictors of MACCE. In contrast, independent predictors of TVR were prior PCI, number of treated vessels, total length of implanted stents and LM lesions (table 6).

\section{DISCUSSION}

Interventional treatment of patients with $\mathrm{CHD}$ is common in China and throughout the world, and its efficacy has been proven in many trials. Numerous 
Table 2 Angiographic findings and interventional characteristics according to clinical presentation

\begin{tabular}{|c|c|c|c|c|c|c|}
\hline & $\begin{array}{l}\text { Urgent PCI } \\
(n=99)\end{array}$ & $\begin{array}{l}\text { Delayed PCI } \\
(520)\end{array}$ & $\begin{array}{l}\text { NSTE-ACS } \\
(1496)\end{array}$ & $\begin{array}{l}S A \\
(n=418)\end{array}$ & $\begin{array}{l}\text { Total } \\
(n=2533)\end{array}$ & p Value \\
\hline Radial artery access, n (\%) & $97(98)$ & $511(98.1)$ & $1458(97.5)$ & $403(96.4)$ & 2469 (97.5) & 0.421 \\
\hline \multicolumn{7}{|c|}{ Number of diseased vessels, $\mathrm{n}(\%)$} \\
\hline 1-vessel disease & $37(37.4)$ & $196(37.6)$ & $614(41.1)$ & $143(34.2)$ & $990(39.1)$ & 0.065 \\
\hline 2-vessel disease & $42(42.4)$ & $197(37.8)$ & $528(35.3)$ & $162(38.8)$ & $929(36.7)$ & 0.3 \\
\hline 3-vessel disease & $20(20.2)$ & $128(24.6)$ & 348 (23.3) & $110(26.3)$ & 606 (23.9) & 0.47 \\
\hline Type B2/C lesion*, n (\%) & $89(52.7)$ & $593(60.1)$ & $1744(64.1)$ & $540(66.1)$ & $2976(63.2)$ & 0.001 \\
\hline Total chronic occlusions, $\mathrm{n}(\%)$ & $9(9.1)$ & $35(6.7)$ & $135(90)$ & $47(11.2)$ & $226(8.9)$ & 0.116 \\
\hline Ostial lesions, n (\%) & $8(8.1)$ & $64(12.3)$ & $154(10.3)$ & $49(11.7)$ & $275(10.9)$ & 0.443 \\
\hline Restenotic lesions, n (\%) & $1(10)$ & $4(0.8)$ & $21(1.4)$ & $8(1.9)$ & $34(1.3)$ & 0.483 \\
\hline Number of treated vessels & $1.36 \pm 0.59$ & $1.55 \pm 0.67$ & $1.5 \pm 0.66$ & $1.57 \pm 0.7$ & $1.52 \pm 0.67$ & 0.12 \\
\hline \multicolumn{7}{|c|}{ Location of target lesions, $\mathrm{n}(\%)$} \\
\hline Left main stem & $1(1)$ & $15(2.9)$ & $45(3)$ & $14(3.3)$ & $75(3)$ & 0.67 \\
\hline LAD & $63(63.6)$ & $405(77.7)$ & $1037(69.4)$ & $314(75.1)$ & $1819(71.8)$ & $<0.001$ \\
\hline LCX & $28(28.3)$ & 175 (33.6) & $573(38.3)$ & $164(39.2)$ & $940(37.1)$ & 0.05 \\
\hline RCA & $43(43.4)$ & $216(41.5)$ & 596 (39.9) & $167(40)$ & $1022(40.3)$ & 0.842 \\
\hline Coronary bypass graft & $0(0)$ & $0(0)$ & $3(0.2)$ & $1(0.2)$ & $4(0.2)$ & 0.722 \\
\hline Number of stents per patient & $2.04 \pm 1.43$ & $2.21 \pm 1.23$ & $2.12 \pm 1.24$ & $2.26 \pm 1.3$ & $2.16 \pm 1.26$ & 0.452 \\
\hline Total stent length per patient & $45.5 \pm 29.1$ & $51.9 \pm 32.1$ & $48.9 \pm 32.4$ & $53.4 \pm 34.6$ & $50.1 \pm 32.6$ & 0.267 \\
\hline Stent diameter $(\mathrm{mm})$ & $3.11 \pm 0.45$ & $3.07 \pm 0.42$ & $3.08 \pm 0.44$ & $3.05 \pm 0.42$ & $3.07 \pm 0.43$ & 0.363 \\
\hline
\end{tabular}

studies have shown higher mortality rates in registries than in randomised clinical trials, ${ }^{13}{ }^{14}$ which is likely because specific populations are examined in randomised trials. In comparison to data from randomised controlled trials, registry data reflecting clinical practice give a more clinically relevant estimate of clinical events as well as TVR rates.

The present study is a follow-up study of patients receiving interventional treatments at our centre over a defined period of time. From the data, we gathered the following information: $7.3 \%$ of patients died, the incidence of MACCE was $13.5 \%$, the incidence of stent thrombosis was $0.7 \%$ and the incidence of TVR was $4.8 \%$. The incidences of in-hospital mortality and major adverse cardiac events were highest in the urgent PCI group. During follow-up, the frequency of TVR was highest in the SA group, and the frequency of in-stent restenosis was highest in the NSTE-ACS group. The

Table 3 Clinical events according to clinical presentation

\begin{tabular}{|c|c|c|c|c|c|c|}
\hline & $\begin{array}{l}\text { Urgent PCI } \\
(n=99)\end{array}$ & $\begin{array}{l}\text { Delayed PCI } \\
(520)\end{array}$ & $\begin{array}{l}\text { NSTE-ACS } \\
(1496)\end{array}$ & $\begin{array}{l}\text { SA } \\
(n=418)\end{array}$ & $\begin{array}{l}\text { Total } \\
(n=2533)\end{array}$ & p Value \\
\hline \multicolumn{7}{|l|}{ In-hospital events, n (\%) } \\
\hline Death & $4(4.0)$ & $5(1.0)$ & $7(0.5)$ & $2(0.5)$ & $18(0.7)$ & $<0.001$ \\
\hline Any Ml & $0(0)$ & $4(0.8)$ & $7(0.5)$ & $4(1.0)$ & $15(0.6)$ & 0.635 \\
\hline MACE & $4(4.0)$ & $9(1.8)$ & $14(1.0)$ & $6(1.5)$ & $33(1.3)$ & 0.001 \\
\hline \multicolumn{7}{|l|}{ Follow-up (cumulated events), n (\%) } \\
\hline Death & $12(12.1)$ & $40(7.7)$ & $108(7.2)$ & $25(6.0)$ & $185(7.3)$ & 0.104 \\
\hline Nonfatal MI & $6(6.0)$ & $24(4.6)$ & $66(4.4)$ & $12(2.9)$ & $108(4.3)$ & 0.414 \\
\hline Nonfatal stroke & $2(2.0)$ & $9(1.7)$ & $17(1.1)$ & $10(2.4)$ & $38(1.5)$ & 0.267 \\
\hline MACCE & $21(21.2)$ & 69 (13.3) & $203(13.6)$ & $49(11.7)$ & $342(13.5)$ & 0.069 \\
\hline Any revascularisation (PCI/CABG) & $6(6.1)$ & $36(6.9)$ & $125(8.4)$ & $33(7.9)$ & $200(7.9)$ & 0.632 \\
\hline TVR & $2(2.0)$ & $15(2.9)$ & 79 (5.3) & $26(6.2)$ & $12(4.8)$ & 0.037 \\
\hline In-stent restenosis & $5(5.1)$ & $17(3.3)$ & 99 (6.6) & $25(6.0)$ & $146(5.7)$ & 0.048 \\
\hline Follow-up angiography & $21(21.2)$ & $100(19.2)$ & $366(24.5)$ & $115(27.5)$ & $603(23.8)$ & 0.018 \\
\hline Stent thrombosis (definite/probable) & $1(1.0)$ & $4(0.8)$ & $9(0.6)$ & $4(1.0)$ & $18(0.7)$ & 0.859 \\
\hline Recurrent angina & $13(13.1)$ & $55(10.6)$ & $173(11.6)$ & $48(11.5)$ & $289(11.4)$ & 0.872 \\
\hline
\end{tabular}


Table 4 Baseline and procedural characteristics according to DES type

\begin{tabular}{|c|c|c|c|c|}
\hline & SES $(n=1650)$ & PES (504) & Total $(n=2154)$ & p Value \\
\hline Age (years) & $59.9 \pm 11.3$ & $59.2 \pm 10.8$ & $59.7 \pm 11.2$ & 0.23 \\
\hline Male gender, n (\%) & $1133(68.7)$ & $336(66.8)$ & 1469 (68.2) & 0.431 \\
\hline BMI $\left(\mathrm{kg} / \mathrm{m}^{2}\right)$ & $22.7 \pm 8.2$ & $22.9 \pm 5.9$ & $22.8 \pm 7.7$ & 0.611 \\
\hline Prior PCI, n (\%) & $119(7.2)$ & $35(7.0)$ & $154(7.2)$ & 0.847 \\
\hline Prior CABG, $n(\%)$ & $13(0.8)$ & $4(0.8)$ & $17(0.8)$ & 1.0 \\
\hline PVD, n (\%) & $5(0.3)$ & $1(0.2)$ & $6(0.3)$ & 1.0 \\
\hline LVEF (\%) & $61.05 \pm 7.33$ & $60.85 \pm 7.9$ & $61.0 \pm 6.4$ & 0.687 \\
\hline Hypertension, n (\%) & $808(49)$ & $229(45.5)$ & 1037 (48.2) & 0.176 \\
\hline Diabetes mellitus, n (\%) & $327(19.8)$ & $99(19.7)$ & $426(19.8)$ & 0.937 \\
\hline Dyslipidaemia, n (\%) & $583(50.2)$ & $230(54.0)$ & $813(51.2)$ & 0.182 \\
\hline Current smoker, n (\%) & $534(32.4)$ & $166(33)$ & $700(32.5)$ & 0.789 \\
\hline Number of treated vessels & $1.45 \pm 0.64$ & $1.36 \pm 0.58$ & $1.43 \pm 0.63$ & 0.002 \\
\hline Number of stents per patient & $2.02 \pm 1.17$ & $1.80 \pm 1.16$ & $1.97 \pm 1.17$ & 0.001 \\
\hline Total stent length per patient & $48.4 \pm 31.5$ & $38.3 \pm 27.2$ & $46.2 \pm 30.9$ & 0.001 \\
\hline Stent diameter (mm) & $3.08 \pm 0.39$ & $3.13 \pm 0.56$ & $3.09 \pm 0.43$ & 0.018 \\
\hline
\end{tabular}

incidences of cardiac death and MI were significantly higher in the PES group than in the SES group.

According to data from other registries, the rate of hospital mortality is higher in patients with STEMI than in patients with NSTE-ACS (7\% and 5\%, respectively). However, 6 months after hospital discharge, the mortality rate is very similar in STEMI and NSTE-ACS patients (12\% vs $13 \%$, respectively). ${ }^{15} 16$ A longer follow-up study showed that in patients who survived until the end of hospitalisation, the mortality rate was two-fold higher in patients with NSTE-ACS than in patients with STEMI. ${ }^{17}$ In these studies, almost all patients with STEMI received urgent PCI. However, in our hospital, most patients came from the countryside; therefore, the majority of those with STEMI were first treated at a local hospital and the survivors were then transferred to our centre for PCI. Consequently, only $16 \%$ of patients with STEMI received urgent PCI; the remaining received delayed PCI. Therefore, we assessed the long-term results of interventional treatment among different groups of patients with $\mathrm{CHD}$.
Controversies over the justification of interventional treatments in all patients with stable CHD and the different strategies to treat patients with NSTE-ACS underline the need to perform such analyses. In the present study, patients with SA accounted for $17 \%$ of the total population. It is worth remembering that current guidelines for patients with SA, particularly after publication of the COURAGE trial, suggest the relevance of PCI in patients who did not benefit from previous pharmacological treatment. ${ }^{18}$ In our study, in comparison with the other groups, patients with SA were older and had a higher frequency of past MI as well as a history of previous revascularisation procedures. The in-hospital mortality rate for patients with SA was $0.5 \%$, which proves the high efficacy and safety of the interventional treatment; the mortality rate at the 29-month follow-up was also low $(6 \%)$.

A reduction in mortality rate is confirmed in patients with STEMI treated with urgent PCI. In our study, 520 patients with STEMI received delayed PCI and $63 \%$ of whom had occluded infarct-related arteries. It is worth noting that current guidelines recommend not

Table 5 Clinical events according to DES type

\begin{tabular}{|c|c|c|c|c|}
\hline & SES $(n=1650)$ & PES (504) & Total $(n=2154)$ & p Value \\
\hline \multicolumn{5}{|l|}{ In-hospital events, n (\%) } \\
\hline Death & $12(0.7)$ & $4(0.8)$ & $16(0.7)$ & 0.879 \\
\hline MI & $9(0.5)$ & $4(0.8)$ & $13(0.6)$ & 0.53 \\
\hline \multicolumn{5}{|l|}{ Follow-up (cumulated events), n (\%) } \\
\hline Death & $119(7.2)$ & $39(7.7)$ & $158(7.3)$ & 0.692 \\
\hline Cardiac death & $68(4.1)$ & $39(7.7)$ & $107(5.0)$ & 0.002 \\
\hline MI & $66(4.0)$ & $33(6.5)$ & 99 (4.6) & 0.032 \\
\hline TVR & $73(4.4)$ & $33(6.5)$ & $106(4.9)$ & 0.054 \\
\hline Any revascularisation (PCI/CABG) & $119(7.2)$ & $51(10.1)$ & $170(7.9)$ & 0.034 \\
\hline In-stent restenosis & $94(5.7)$ & $39(7.7)$ & $133(6.2)$ & 0.514 \\
\hline Stent thrombosis (definite/probable) & $9(0.5)$ & $4(0.8)$ & $13(0.6)$ & 0.744 \\
\hline
\end{tabular}


Table 6 Multivariate analysis of predictors of death, MACCE and TVR

\begin{tabular}{|c|c|c|c|}
\hline & Wald's $\chi^{2}$ & HR $(95 \% \mathrm{Cl})$ & p Value \\
\hline \multicolumn{4}{|l|}{ Death } \\
\hline Age (years) & 21.3 & $1.08(1.05$ to 1.12$)$ & $<0.001$ \\
\hline LVEF $<40 \%$ & 31.4 & 3.28 (2.16 to 4.98$)$ & $<0.001$ \\
\hline Diabetes mellitus & 7.35 & 2.38 (1.27 to 4.48$)$ & 0.007 \\
\hline Prior CABG & 11.74 & 13.9 (3.09 to 63$)$ & 0.001 \\
\hline Chronic total occlusion & 9.1 & 2.93 (1.46 to 5.88$)$ & 0.003 \\
\hline \multicolumn{4}{|l|}{ MACCE } \\
\hline Age (years) & 12.6 & 1.03 (1.01 to 2.2$)$ & $<0.001$ \\
\hline LVEF $<40 \%$ & 9.39 & 2.79 (1.45 to 5.39$)$ & 0.002 \\
\hline Multi-vessel disease & 5.99 & 1.66 (1.11 to 2.49$)$ & 0.014 \\
\hline Diastolic blood pressure & 5.59 & $1.02(1.0$ to 1.03$)$ & 0.018 \\
\hline Chronic total occlusion & 5.26 & 1.71 (1.08 to 2.71$)$ & 0.022 \\
\hline Target vessel=LM & 9.38 & 2.79 (1.45 to 5.39$)$ & 0.002 \\
\hline \multicolumn{4}{|l|}{ TVR } \\
\hline Prior PCI & 9.84 & 3.01 (1.51 to 5.98$)$ & 0.002 \\
\hline Number of treated vessel & 11.61 & 1.76 (1.27 to 2.45$)$ & 0.001 \\
\hline Total length of implanted stents (per 10-mm length) & 1.23 & 1.23 (1.03 to 1.62$)$ & 0.001 \\
\hline LM lesion & 5.78 & 3.06 (1.23 to 7.64$)$ & 0.016 \\
\hline
\end{tabular}

performing delayed PCI on a totally occluded infarct-related artery $24 \mathrm{~h}$ after STEMI in asymptomatic patients with 1-vessel or 2-vessel disease if they are haemodynamically and electrically stable and show no evidence of severe ischaemia. ${ }^{19}$ Our data were collected before this guideline was published; therefore, the data were not further classified on the basis of different clinical conditions. Far fewer deaths occurred during hospitalisation and the follow-up in the delayed PCI group than in the urgent PCI group; however, mortality rates in both groups markedly increased during the follow-up. In contrast to a previously published study, ${ }^{20}$ in which all patients with NSTE-ACS received early interventional treatment after confirming that they had ACS (within $24 \mathrm{~h}$ of hospital admission), only high-risk patients received early intervention in the present study. Similar to a previous study, ${ }^{20}$ the mortality rate of the NSTE-ACS group significantly increased from $0.5 \%$ during hospitalisation to $7.2 \%$ during the 29-month follow-up. These results are in line with current knowledge of ACS, ${ }^{15-17}$ and could be associated with more complex lesions prior to PCI (table 2). Although mortality in the delayed PCI group was lower than in the urgent PCI group, it increased markedly during the follow-up. The higher long-term mortality in patients with STEMI compared with patients with NSTE-ACS observed in our study is inconsistent with previous studies. This may be owing to the poorer systolic function of the left ventricle and a higher frequency of renal insufficiency in the urgent PCI and delayed PCI groups than in the NSTE-ACS and SA groups. In the present study, both in-hospital and follow-up mortality rates were lower than those reported in a previous study, ${ }^{20}$ which is mainly due to the different proportion of patients who underwent urgent PCI (3.9\% vs $50 \%)$.
In a recent multi-centre registry, ${ }^{11}$ in-hospital mortality, MI and MACE (death/MI) rates were similar to those observed in our study. However, during a mean follow-up of 4.1 years, the incidences of clinical events were higher in the multi-centre registry than in our study, especially the rates of any revascularisation (PCI/ CABG) and TVR. There are several possible explanations for this. First, patients in this registry were older and had higher frequencies of diabetes mellitus, arterial hypertension, renal insufficiency, and a history of prior MI and previous revascularisation procedures. In addition, the proportion of patients presenting with STEMI was higher in this previous study than in the current study. All these factors are well-known risk factors for adverse clinical events. Second, China is a developing country where health insurance and costs are likely to deter most patients from undergoing subsequent revascularisation procedures. As shown in table 3, $11.4 \%$ of patients experienced recurrent angina, which was treated by medication, not by surgery. This might be the main reason for the lower rates of revascularisation (PCI/CABG) and TVR observed in the current study. In addition, we must take into consideration the influence of different ethnic groups.

There is a large variation in the incidence of sent thrombosis among previous studies. The incidence of sent thrombosis observed in our study $(0.7 \%)$ is similar to that reported in four randomised DES trials (RAVEL, SIRIUS, C-SIRIUS and E-SIRIUS). These trials reported that the 4-year rate of sent thrombosis, according to the Academic Research Consortium definitions, was $0.7 \%$ and $0.4 \%$ in patients who received DESs and BMSs, respectively, when only definite and probable sent thrombosis were considered. ${ }^{21-24}$ However, the 
incidence of sent thrombosis was much higher in other studies. ${ }^{25}{ }^{26}$ Sent thrombosis is a complex multifactorial syndrome, and the individual characteristics of patients and lesions as well as clinical and procedural factors all contribute to its risks. Therefore, it is likely that different baseline clinical and angiographic characteristics account for the differences observed in previous studies.

In recent years, stent strut, polymer and cytotoxic drugs have evolved significantly; cytotoxic drugs were mainly the derivatives of rapamycin and paclitaxel. In order to facilitate the description, we simply divided patients into two categories: SES or PES. A previous study ${ }^{9}$ demonstrated that SES is better than PES in terms of late stent thrombosis and target lesion revascularisation. In our study, patients were recruited after the publication of the study. The selection of stent type was left to the surgeon's discretion; therefore, there may be a selection bias. The sample size was small in the PES group, and statistically significant differences were observed in the number of treated vessels, the number of stents per patient, the total stent length per patient and the stent diameter between the SES and PES groups; thus, attention should be paid to the interpretation of the results. Nevertheless, our results are consistent with another previous study. ${ }^{27}$

In the present study, older age was an independent predictor of death. This has been observed in most studies assessing the long-term results of treatment, ${ }^{28}$ and may be due to the many additional burdens that are typical of older people, which may influence the long-term follow-up. Prior CABG and chronic total occlusion as predictors of long-term death may be the result of more complex lesions and more severe myocardium damage, thereby worsening long-term prognosis. Diabetes mellitus and a low LVEF are well-known risk factors for adverse cardiovascular events in patients with CHD.

Similar to a previous study, ${ }^{11}$ our study showed that age, reduced left ventricular function (LVEF $<40 \%)$, and multi-vessel disease were predictors of MACCE. All of these factors are well-known adverse clinical factors for PCI. Previous studies have identified other clinical variables, including diabetes mellitus, renal insufficiency, prior MI and cardiogenic shock, as well as angiographic variables, such as bypass graft as target vessel, as predictors of MACCE. Our study did not find any significant statistical differences in these variables among the groups; this may be due to the small number of events and patients in each of these categories.

In our study, prior PCI, number of treated vessels, total length of stents implanted and LM lesions were predictors of the occurrence of TVR. In contrast to a previous study, ${ }^{11}$ target vessel=coronary bypass and ostial lesions were not predictors of the occurrence of TVR in our study. This may be due to the lower frequency of PCI with coronary bypass graft in our study as well as the different strategies used to treat ostial lesions.

In summary, it is worth emphasising that the present study proves the safety and efficacy of DESs in everyday practice and provides additional information on the long-term results of PCI in China.

\section{Study limitation}

This is an observational single-centre registry and may have an inherent bias common to this type of study. Furthermore, follow-up angiography was only performed on $23.8 \%$ of patients; therefore, the rate of in-stent restenosis might be underestimated. In recent years, DES has evolved significantly. Production of some types of stents have been stopped (eg, cipher), and some new stents have been used widely (eg, XIENCE V). Hence, this study did not exactly reflect current real world practice and clinical outcomes. We also did not have data on stent strut thickness and the type of stent platform used. Lastly, echocardiography was performed in a small proportion of patients with STEMI in urgent PCI group. Therefore, this might affect the reliability of the parameter of LV systolic function in these patients.

\section{CONCLUSIONS}

Data from a 'real-world' registry on the use of DESs in 2533 patients showed that both the early and long-term prognosis of patients with CHD undergoing PCI depends on clinical presentation as follows: (1) patients with STEMI had the worst prognosis, while patients with stable CHD had the best prognosis; (2) the mortality rate after hospital discharge increased markedly in the NSTE-ACS group; and (3) the incidences of cardiac death and MI were lower with SESs than with PESs. The most well-recognised risk factors for death in patients with CHD are still of great importance for the negative prognosis of patients after PCI. The main predictors of MACCE were clinical and angiographic parameters, whereas the predictors of TVR were angiographic and interventional parameters.

\section{Author affiliations \\ ${ }^{1}$ Department of Cardiology, The First Affiliated Hospital of Zhengzhou University, Zhengzhou, People's Republic of China \\ ${ }^{2}$ Department of Integrated ICU, The First Affiliated Hospital of Zhengzhou University, Zhengzhou, People's Republic of China}

Acknowledgements The manuscript was checked and edited by $\mathrm{Dr}$ Cecilia Devoto and Mrs Judith Hindley (Bioedit Ltd, UK).

Contributors H-MY participated in the coordination of the study, the study design, interpretation of the results and manuscript drafting. H-MY, Y-DW and $X$-JZ participated in the study design, performed the analysis and interpreted the results. D-LS, J-YZ and LL contributed to the study design and interpretation of the results. L-SZ and T-WS contributed to the study design and provided feedback on the manuscript. T-WS conceived the study, participated in its design and interpretation, helped to draft the manuscript and provided feedback on the manuscript. All authors read and approved the final manuscript.

Funding This study was supported by the National Natural Science Foundation of China (Grant No. 81370364), The program for Science and Technology Innovation of the Henan Province (N0.201203035), an Innovative Investigators Project Grant from the Health Bureau of the Henan Province, a Program Grant for Science \& Technology Innovation Talents in Universities of the Henan Province (2012HASTIT001), the Henan Provincial Science and 
Technology Achievement Transformation Project (122102310581), the Henan Province of Medical Scientific Province \& Ministry Research Project (201301005) and the Henan Province of Medical Scientific Research Project (201203027), China.

\section{Competing interests None.}

Ethics approval The ethics committee of The First Affiliated Hospital of Zhengzhou University and complied with the Declaration of Helsinki.

Provenance and peer review Not commissioned; externally peer reviewed.

Data sharing statement Extra data can be accessed via the Dryad data repository at http://datadryad.org/ with the doi:10.5061/dryad.13d31.

Open Access This is an Open Access article distributed in accordance with the Creative Commons Attribution Non Commercial (CC BY-NC 3.0) license, which permits others to distribute, remix, adapt, build upon this work noncommercially, and license their derivative works on different terms, provided the original work is properly cited and the use is non-commercial. See: http:// creativecommons.org/licenses/by-nc/3.0/

\section{REFERENCES}

1. Degertekin M, Regar E, Tanabe K, et al. Sirolimus-eluting stent for treatment of complex in-stent restenosis: the first clinical experience. J Am Coll Cardiol 2003;41:184-9.

2. Sousa JE, Costa MA, Abizaid A, et al. Lack of neointimal proliferation after implantation of sirolimus-coated stents in human coronary arteries: a quantitative coronary angiography and three-dimensional intravascular ultrasound study. Circulation 2001;103:192-5.

3. Tanabe K, Serruys PW, Grube E, et al. TAXUS III Trial: in-stent restenosis treated with stent based delivery of paclitaxel incorporated in a slow-release polymer formulation. Circulation 2003;107:559-64.

4. Colombo A, Drzewiecki J, Banning A, et al. Randomized study to assess the effectiveness of slow- and moderate-release polymer-based paclitaxel-eluting stents for coronary artery lesions. Circulation 2003;108:788-94.

5. Hong MK, Mintz GS, Lee CW, et al. Paclitaxel coating reduces in-stent intimal hyperplasia in human coronary arteries: a serial volumetric intravascular ultrasound analysis from the Asian Paclitaxel-Eluting Stent ClinicalTrial (ASPECT). Circulation 2003;107:517-52

6. Moses JW, Leon MB, Popma JJ, et al. Sirolimus-eluting stents versus standard stents in patients with stenosis in a native coronary artery. N Engl J Med 2003;349:1315-23.

7. Park SJ, Shim WH, Ho DS, et al. A paclitaxel-eluting stent for the prevention of coronary restenosis. N Engl J Med 2003;348:1537-45.

8. Stone GW, Ellis SG, Cox DA, et al. A polymer-based, paclitaxeleluting stent in patients with coronary artery disease. $N$ Engl J Med 2004;350:221-31.

9. Stettler C, Wandel S, Allemann S, et al. Outcomes associated with drug-eluting and bare-metal stents: a collaborative network meta-analysis. Lancet 2007;370:937-48.

10. Zahn R, Hamm CW, Schneider S, et al. Predictors of death or myocardial infarction during follow-up after coronary stenting with the sirolimus-eluting stent. Results from the prospective multicenter German Cypher Stent Registry. Am Heart J 2006;152:1146-52.

11. Zahn R, Neumann FJ, Buttner HJ, et al. Long-term follow-up after coronary stenting with the sirolimus-eluting stent in clinical practice: results from the prospective multi-center German Cypher Stent Registry. Clin Res Cardiol 2012;101:709-16.

12. Lincoff AM, Bittl JA, Harrington RA, et al. Bivalrudin and provisional. glycoprotein Ilb/llla blockade compared with heparin and planned glycoprotein Ilb/llla blockade during percutaneous coronary intervention: the REPLACE-2 randomized trial. JAMA 2003;289:853-63.

13. Grootendorst DC, Jager KJ, Zoccali C, et al. Observational studies are complementary to randomized controlled trials. Nephron Clin Pract 2010;114:c173-7.

14. Hannan EL. Randomized clinical trials and observational studies: guidelines for assessing respective strengths and limitations. JACC Cardiovasc Interv 2008;1:211-17.

15. Volmink JA, Newton JN, Hicks NR, et al. Coronary event and case fatality rates in an English population: results of the Oxford myocardial infarction incidence study. The Oxford Myocardial Infarction Incidence Study Group. Heart 1998;80:40-4.

16. Savonitto S, Ardissino D, Granger CB, et al. Prognostic value of the admission electrocardiogram in acute coronary syndromes. JAMA 1999;281:707-13.

17. Terkelsen CJ, Lassen JF, Nørgaard BL, et al. Mortality rates in patients with ST-elevation vs. non-ST-elevation acute myocardia infarction: observations from an unselected cohort. Eur Heart $J$ 2005;26:18-26.

18. Boden WE, O'Rourke RA, Teo KK, et al.; COURAGE Trial Research Group. Optimal medical therapy with or without PCI for stable coronary disease. N Engl J Med 2007;356:1503-16.

19. O'Gara PT, Kushner FG, Ascheim DD, et al. 2013 ACCF/AHA Guideline for the Management of ST-Elevation Myocardial Infarction: a report of the American College of Cardiology Foundation/American Heart Association Task Force on Practice Guidelines. Circulation 2013;127:e362-425.

20. Kozuch M, Kralisz P, Korecki J, et al. Early and long-term prognosis of patients with coronary artery disease treated with percutaneous coronary interventions in 2005. Experience of single large-volume $\mathrm{PCl}$ center. Adv Med Sci 2011;56:222-30.

21. Schampaert E, Moses JW, Schofer J, et al. Sirolimus-eluting stents at two years: a pooled analysis of SIRIUS, E-SIRIUS, and C-SIRIUS with emphasis on late revascularizations and stent thromboses. Am J Cardiol 2006;98:36-41.

22. Morice MC, Serruys PW, Barragan $\mathrm{P}$, et al. Long-term clinical outcomes with sirolimus-eluting coronary stents: five-year results of the RAVEL trial. J Am Coll Cardiol 2007;50:1299-304.

23. Weisz G, Leon MB, Holmes DR, et al. Two-year outcomes after sirolimus-eluting stent implantation: results from the Sirolimus-Eluting Stent in de Novo Native Coronary Lesions (SIRIUS) trial. J Am Coll Cardiol 2006;47:1350-5.

24. Spaulding C, Daemen J, Boersma E, et al. A pooled analysis of data comparing sirolimus-eluting stents with bare-metal stents. $N$ Engl J Med 2007;356:989-97.

25. Flores-Ríos X, Marzoa-Rivas R, Abugattás-de Torres JP, et al. Late thrombosis of paclitaxel-eluting stents: long-term incidence, clinical consequences, and risk factors in a cohort of 604 patients. Am Heart J 2008;155:648-53.

26. Daemen J, Wenaweser P, Tsuchida K, et al. Early and late coronary stent thrombosis of sirolimus eluting and paclitaxel-eluting stents in routine clinical practice: data from a large two-institutional cohort study. Lancet 2007;369:667-78.

27. Park K, Park KW, Rha SW, et al. Comparison of 5-year clinical outcomes between sirolimus-versus paclitaxel-eluting stent: Korean multicenter network analysis of 9000-patient cohort. Circ Cardiovasc Interv 2012;5:174-84.

28. He F, Zhang J, Lu ZQ, et al. Risk factors and outcomes of acute kidney injury after intracoronary stent implantation. World $J$ Emerg Med 2012;3:197-201. 